\title{
APROXIMACIÓN AL LENGUAJE DE LAS CAMISETAS CON PALABRAS
}

\author{
Ricardo MORANT MARCO \\ Universitat de València \\ ricardo.morant@uv.es
}

Resumen: Este artículo estudia la función, la forma y el uso de las camisetas con mensajes escritos. Estas prendas, cuyo empleo correcto exige tener en cuenta el contexto comunicativo, se distinguen por su polivalencia, por su fuerza expresiva y concisión.

Abstract: This is a study of the function, form and use of T-shirts featuring written messages. These articles of clothing, whose correct use requires the consideration of the communicative context, are characterized not only by theirall-purpose nature, but also by their expressive power and conciseness.

Palabras clave: Lenguaje de la ropa. Mensajes escritos. Medio de comunicación.

Key Words: Clothing language/discourse. Written messages. Mass media. 


\section{INTRODUCCIÓN}

$\mathrm{Al}$ estudiar el ámbito de la indumentaria nos damos cuenta inmediatamente de que el atuendo no sólo sirve para protegernos, sino también para transmitir determinadas informaciones. En palabras de Tannen, las ropas que vestimos además de cubrirnos y mantenernos abrigados:

[...] también revelan el tipo de persona que somos y nuestras actitudes con respecto a cada situación. Vestir un traje de tres piezas puede señalar un estilo formal (chapado a la antigua) o respeto por la ocasión; vestir jeans puede señalar un estilo informal (o zarrapastroso) o no tomar la ocasión con seriedad (1999: 43).

García Fernández por su parte, señala que, además de la actitud y de la habilidad de la persona para adecuarse a los distintos contextos, la ropa que vestimos puede aportar otros datos, por ejemplo:

-Identidad: mediante la vestimenta puede identificarse el rol y el estatus de la persona: edad, sexo, religión, ocupación, clase social, status transitorio (celebración, boda...), actividad deportiva.

-Expresión de estados de ánimo: [...] especialmente a través de los colores: rojo, negro, amarillo, azul.

-Integración cultural: moda imperante, patrones de belleza, contracultura (2000: 142).

Toda esta información sobre la manera de ser, de pensar o de actuar se puede transmitir de dos maneras: de una forma no verbal, luciendo o prescindiendo de determinadas prendas (velo, gorra, minifalda...) o de una manera verbal, mediante la anotación de ciertos mensajes en la ropa de vestir. Esta última modalidad, la que según P. Calefato (2002) convierte la indumentaria en página de escritura, tiene cada vez más partidarios. Un caso curioso de esta tendencia en la que se envuelve el cuerpo con textos, en el que se une traje y escritura, es el adiós por escrito que protagonizó Marie Laure, mujer del ex primer ministro francés, Dominique de Villepin, al abandonar éste su cargo el día 17 de mayo de 2007. Ésta, para la despedida, escogió un traje en el que aparecía impreso el vocablo adiós, además de en español, en italiano, en portugués y en inglés, o sea un vestido adornado con las palabras adiós, ciao ciao, salut y bye-bye.

Pero no hace falta recurrir a actos extraordinarios para encontrar muestras de ropa comunicante. Nuestras calles están repletas de ejemplos. ¿Quién no ha visto mientras paseaba a una joven vestida con una falda que dice «Rebelde», o con unos pantalones que en las posaderas lleva la ins- 
cripción «Delicious», o a un miembro de las fuerzas de seguridad locales en cuyo uniforme se especifica «Policía Municipal»? Parece que la ropa se ha convertido en una pizarra y sus comunicados se exponen tanto en las prendas que se lucen por fuera como en la ropa interior. Sobre esta última moda apareció una noticia en la página 19 del diario gratuito 20 minutos del 18 de septiembre de 2007, en la que se revelaba el tipo de bragas que gustan a las españolas. En ese artículo de prensa se reseñaba que:

En la lencería con palabras, las leyendas que más gustan son Only for you (sólo para ti), seguida de Kiss and tell (besa y dime) y de Let's dream together (soñemos juntos). Con estas prendas, las mujeres entrevistadas dicen querer «sorprender a sus parejas», «romper la rutina»y «sentirse más juveniles».

Nosotros no vamos a examinar los mensajes de las prendas íntimas ni de los vestidos masculinos y femeninos, tan sólo reflexionaremos sobre la fraseología exhibida en las camisetas, en esas telas que empezaron a ganar prestigio gracias al séptimo arte ${ }^{1}$ a mediados del siglo $\mathrm{xx}$ y que hoy se han convertido en una pieza básica de cualquier armario ropero joven.

Para conseguir nuestro propósito, la caracterización (función, rasgos y usos) de las camisetas con palabras, hemos recogido, clasificado, descrito y explicado una muestra constituida por más de quinientas de estas prendas. Este corpus representativo se ha obtenido acudiendo a determinadas comercios y navegando por tiendas on line (Kamisetas.com, Seta Loca, DirtyFashion, etc.), revisando los armarios de amig@s y conocid@s, y explorando el paisaje mediático, literario y callejero. Esta tarea, aparentemente sencilla, no es fácil, ya que exige tener los ojos muy atentos. Sin esta mirada especial, que requiere captar hasta el más mínimo detalle de la ropa analizada, difícilmente se puede llevar a cabo un estudio de este tipo, puesto que todas las camisetas tienen algo que enseñarnos, son un espejo del/ de la portador/-a y de la sociedad en la que vive.

\section{EL LENGUAJE DE LAS CAMISETAS}

En nuestros itinerarios cotidianos, especialmente durante el verano, nos tropezamos con infinidad de camisetas. Éstas se han convertido en un medio de comunicación significativo, porque, además de ser cómodas y combinar con casi todo, «cuestan poco y valen mucho».

${ }^{1}$ Las camisetas no vinieron al mundo ni con James Dean ni con Marlon Brando, pero su uso se extendió a raíz de las películas Rebeldes sin causa y El salvaje. 


\subsection{Función}

Estas prendas con voz, además de resultar baratas destacan porque sirven para todo, aunque no siempre se han utilizado con la misma finalidad, han experimentado una evolución como demuestra P. Calefato en el siguiente texto:

Las camisetas adornadas con palabras pueblan las escenas de la moda, al menos desde hace treinta años, y se trata de una costumbre que sigue originariamente dos corrientes: por un lado la más «europea» del paso de la firma (Chanel, CD, Cacharel, etc.) de dentro hacia fuera (como se decía antes), es decir, de la etiqueta interna a «todo el campo» externo; por el otro, la corriente más americana de la tradicional inscripción sobre la camiseta del nombre o del símbolo del campus de pertenencia o del equipo de fútbol, rugby o béisbol preferido. Sobre estas dos corrientes se fue introduciendo posteriormente la moda de escribir sobre la camiseta el nombre de los grupos o cantantes de rock de culto, o frases más o menos banales tipo «Yo Amo París», «Paz», «Amor», «French Kiss», «Italians do it better» u otras. Pero la verdadera explosión tuvo lugar en el último decenio, cuando se descubrió que era posible hacer del cuerpo revestido por una camiseta una verdadera página de escritura, incluso literaria: poesías más o menos célebres, letras de canciones, frases de doble sentido o eslóganes políticos, todo ello sirvió para hacer de una simple camiseta una pieza fuerte de la elegancia y del estilo (2002: 81).

Las camisetas con palabras, por tanto, se emplean con diversos fines y así, tenemos desde las publicitarias o solidarias, hasta las conmemorativas, las comerciales o las reivindicativas, pasando por las seductoras o las filosóficas. Cuando se analizan las primeras, las utilizadas como reclamo publicitario, comprobamos que al igual que muchos autobuses se han convertido en «anuncios sobre ruedas», estas camisetas transforman a muchas personas en verdaderos «anuncios vivientes». Con ellas la gente se convierte en publicidad ambulante: porta el logo o el lema de una institución, una empresa, un partido y lo pasea allá donde va. Estas prendas se regalan, se cambian por puntos, se lanzan en acontecimientos musicales (conciertos), deportivos (maratones populares), etc. Igual hacemos propaganda de los yogures $D a$ none que exhibimos el lema de Ron Barceló: «Mi oscuro deseo». En relación con este tipo de camisetas llaman la atención las que parodian bien el logo (el de Pepsi se convierte en Sexsy), o bien el eslogan (el «Siempre Coca-Cola» se transforma en «Siempre Colo-Cados») de conocidas multinacionales.

Aparte de las publicitarias, destacan las camisetas comerciales, las que se venden con fines puramente lucrativos, y entre éstas sobresalen al menos dos 
grandes grupos. Por un lado, destacan las diseñadas por los grandes modist@s como Dolce \& Gabbana, Carolina Herrera, Calvin Klein, cuyas marcas suelen ser el único mensaje impreso. Estos distintivos, según Á. López (1998: 112), resultan fundamentales en esta sociedad del escaparate, ya que son como las estrellas y galones de la sociedad civil, que se llevan en el pecho y cuya finalidad es «exhibir un cierto grado de capacidad adquisitiva». Estas marcas, nacidas para diferenciar, han ido cambiando de ubicación y de tamaño a lo largo del tiempo tal y como se ve en el siguiente texto de $\mathrm{N}$. Klein:

Hasta principios de la década de 1970, las etiquetas con los logos de la ropa estaban por lo general ocultas a la vista, discretamente situadas bajo el cuello. Es verdad que en el exterior de las camisas aparecían pequeños emblemas del diseñador, pero estas lindezas se limitaban a las canchas de golf y de tenis de los ricos. Hacia finales de la misma década, cuando el mundo de la moda se rebeló contra los oropeles de Aquarian, la ropa deportiva de la década de 1950 fue adoptada por unos padres que habían regresado al conservadurismo y por sus guapetones hijos. El jinete de Ralph Lauren y el caimán de Lacoste escaparon de las pistas de golf y se deslizaron a las calles, y fueron decisivos para que el logo pasara al exterior de las camisas. Estos logos cumplían la misma función que el acto de conservar en las ropas la etiqueta de los precios: todo el mundo podía saber cuánto estaba dispuesto a pagar quien las llevaba. A mediados de la década de 1980, a Ralph Lauren y Lacoste se les unieron Calvin Klein, Esprit y, en Canadá, la marca Rotos. Gradualmente, el logo pasó de ser una afectación ostentosa para convertirse en un accesorio esencial de la moda. Lo más significativo fue que el propio logo aumentó de tamaño, y de ser un pequeño emblema se convirtió en un cartel del tamaño del torso humano. Este proceso de aumento del tamaño del logo sigue adelante, y ninguno ha llegado al de las dimensiones de Tommy Hilfiger, que se las ha ingeniado para inaugurar un estilo de ropa que transforma a sus fieles seguidores en muñecos andantes, hablantes y de tamaño natural, momificados en mundos totalmente marcados con su logo (2001: 56).

Continuando con las palabras de esta autora, la importancia de estos logos ha sido tal que «han trasformado sustancialmente las prendas donde aparecen convirtiéndolas en simples portadoras de las marcas que representan».

Entre las camisetas comerciales sobresalen, por otro lado las deportivas, especialmente las de las estrellas de los equipos de fútbol de primera división, en las que, además de los colores del club, figuran el número y el nombre del famoso jugador. Entre los deportistas más vendedores de estas prendas despuntan Ronaldinho o Beckham. Tan importantes son las ganan- 
cias que se recaudan por este concepto en los equipos grandes, que para aumentar los beneficios en concepto de merchandising se realiza cada año la presentación del uniforme oficial para la nueva temporada. Por ejemplo, el día 11 de junio de 2007, el delantero Raúl González y el presidente del Real Madrid, Ramón Calderón, presentaron la camiseta oficial de su club. El jugador la mostró a los medios para darla a conocer y el máximo dirigente del equipo merengue aprovechó la ocasión para decir: «Es la camiseta de la décima Copa de Europa». La finalidad perseguida en este tipo de acontecimientos es doble: primero, beneficiar al patrocinador del equipo, que consigue impacto mediático y por tanto, espacio y tiempo en los más importantes medios de comunicación; el segundo objetivo es promocionar la prenda para que los hinchas de los deportistas adquieran la nueva y costosa indumentaria.

A continuación nos centraremos en las camisetas solidarias, o sea, en las que se comprometen con el dolor o con la causa de una persona o de un colectivo. Solidaria se puede considerar la camiseta pro Kate con la que salió a saludar al público el creador de moda londinense, Alexander McQueen, al acabar el desfile realizado en París en el que presentaba su colección de primavera-verano para el año 2006. En esta prenda, que aludía a la modelo Kate Moss, que atravesaba un mal momento tras el escándalo de la cocaína en el que se vio implicada, aparecía impresa la frase «We love you Kate».

Existen, asimismo, las camisetas solidarias que se venden con el fin de recaudar fondos para una causa justa. A una de ellas va referida la siguiente noticia publicada en 20 minutos el 20 de abril de 2007:

El doctor House hace camisetas con sus mejores frases y fines solidarios. Gregory House es el médico más gruñón de la pequeña pantalla, pero también el más popular gracias a la serie que lleva su apellido, House. El doctor da ahora muestras de tener un buen corazón con la venta de camisetas para causas benéficas. En ellas se estamparán sus frases más ocurrentes y contundentes, como «Todo el mundo miente» $o$ «La humanidad está sobrevalorada». La cadena estadounidense Fox, encargada de la serie, quiere dar muestras de su benevolencia con la venta de camisetas desde la página www.Housecharitytees.com. Los beneficios que obtenga los destinará a la Alianza Nacional Para Enfermos Mentales.

Nos parece interesante para acabar con el apartado de las camisetas solidarias la siguiente reflexión que sobre esta clase de prendas realizó el periodista y escritor Francisco Umbral en el diario El Mundo, el 18 de abril de 1997: 
Pero es significativo que las ideas y las creencias hayan bajado de la cabeza al corazón. Resulta favorable que en un tiempo de ordenadores la gente vuelva a pasarse las cosas por el corazón (que eso quiere decir el verbo recordar), pero si lo pensamos un poco más ocurre que las imágenes, los mitos, las ideas, las revoluciones, la ecología y sus delfines, los de Chiapas y su guerra, todo se queda en la superficie, en la camiseta, como un falso tatuaje, no impregnan la piel ni nos encurte por dentro. Llevamos nuestras convicciones, preferencias y marcas al aire, pero en cuanto uno se quita la camiseta, para la lavandería, todo el mensaje subversivo, progre, ácrata, automovilístico o dietético se va con la ropa sucia. Cambiamos de camiseta solidaria y cambiamos de ideario, pues las camisetas son variadas y en la siguiente se anuncian otros coches, otros galanes, otros líderes, otros rockeros, otras guerras, otras ballenas. Ideologías de usar y tirar, como son las del hombre unidimensional de este fin de milenio. Nos tatuamos sobre la piel todo un código personal, como los indios, pero al día siguiente cambiamos de camiseta y de código. Cuando la gente llevaba cuatro ideas en la cabeza, y no cuatrocientas en la camiseta, el mundo me parece a mí que iba mejor.

Junto a las camisetas benéficas están las conmemorativas, las que se llevan en determinados eventos. Estas prendas, por ejemplo, se han convertido en un elemento imprescindible en la celebración de numerosas fiestas populares. En ellas, la camiseta ha pasado a ser el uniforme de batalla mientras dura(n) esa(s) jornada(s) festiva(s). Para su diseño, en unos casos se acude a un experto y en otros, para evitar gastos, se crea entre todos. En este último caso, además de contar con el asesoramiento de los vecinos locales, se llega incluso a solicitar consejo a los vecinos globales. En Internet, por ejemplo, encontramos la siguiente petición de ayuda:

Estamos buscando frases chulas para hacer una camiseta para la fiesta de la primavera del día 23 en Granada (España), por favor si podéis darnos ideas os lo agradeceremos. Queremos ponernos las tías una frase y los tíos otra (http://espanol.answers.yahoo.com/question/index?qid=20070314074855AAi6DVt).

Este fenómeno, el de las camisetas conmemorativas de quintos, peñas, mayorales, etc. se ha popularizado y al analizar la fraseología que aparece impresa observamos que, entre los mensajes preferidos, predominan los relacionados con la bebida. La incitación al consumo de alcohol se exhibe en estas prendas, bien en plan jeroglífico ( $\mathrm{BB}+»)$, bien de manera paródica ( Ceda el vaso»). Parece que la bebida constituye un elemento festivo imprescindible, que es inconcebible una fiesta «libre de alcohol», que continúa en vigor el lema «bebo, luego me divierto». 
Otra clase de camisetas dignas de comentario son las reivindicativas, las que denuncian las injusticias, las que luchan por los más débiles, los invisibles, los sin voz. Entre éstas se hizo famosa la que gritaba «No a la guerra» durante el preludio y el inicio del conflicto bélico acaecido en Irak. En esta prenda, que lucieron actores e intelectuales en señal de protesta durante numerosos acontecimientos públicos, según su creadora la actriz Pilar Ordóñez, todo estaba muy bien pensado, desde el color (el rojo en las letras para recordar la sangre y el fondo negro para evocar el luto de las familias) hasta las palabras elegidas (la negación No en primer lugar y en grande).

Ahora bien, no sólo hay quejas por causas internacionales. También encontramos prendas que gritan contra injusticias que tienen lugar en nuestro país. Lucía Etxebarría, por ejemplo, en la página veinticuatro del diario $A D N$ del 18 de junio de 2007, hacía alusión a una de estas camisetas, protestaba del modo siguiente:

El otro día en la Feria del Libro me encontré con una chica monísima que iba disfrazada de Super Vivienda, esto es: traje de superwoman con mallas, maillot y capa al uso, y en la capa bordada un 47 enorme, el número del artículo de nuestra constitución que proclama el derecho a una vivienda digna. Iba acompañada de un chico en cuya camiseta se leía la siguiente leyenda estampada: «No vas a tener casa en la puta vida». Me contaron que se habian acercado a la caseta en la que estaba firmando ejemplares la Presidenta de esta nuestra Comunidad (ya saben que en la Comunidad de Madrid La Esperanza es lo último que se pierde) y que seguridad les había impedido que se acercasen a la ínclita firmante.

Resultan, asimismo, interesantes las camisetas seductoras, las que juegan un papel fundamental a la hora de ligar. Entre estas prendas conviene diferenciar, primeramente, las que pretenden facilitar el inicio de una relación, las que intentan romper el hielo. A este grupo pertenecen aquellas en las que aparece impreso el nombre de la persona que la luce, uno de los primeros datos que uno trata de averiguar cuando conoce a alguien y le gusta. En este mismo apartado entrarían las camisetas que tratan de arrancar una sonrisa, ya que este gesto expresa apertura, receptividad, alegría, comprensión. En palabras de Hogue (2000: 151): «si deseas iniciar una conversación con alguien, nada mejor que una sonrisa» y qué mejor que presentarse públicamente con frases divertidas del estilo de «Soy un tío moderno: igual frío una camiseta que plancho un huevo». En un segundo grupo estarían las camisetas propiamente seductoras, «que transforman el cuerpo escrito por la camiseta en un cuerpo deseable», bien ensalzando el físico ( $\ll 100 \%$ libre de silicona»), bien el carácter («Soy pija (pero molo mogollón)») o destacando 
otros rasgos ( «Soltero. Casa. Coche) del/ de la portador/a. Finalmente, tendríamos otro grupo con las camisetas en las que se especifica el perfil de la persona buscada ( I like a boy as Beckham») o las intenciones («¿Quieres salir conmigo?»). Algunas mujeres, sabedoras de lo que buscan ciertos hombres, al menos por los mensajes que portan («Profesor de sexo. Primera clase...gratis»), se ponen a la defensiva y para espantarlos, lucen advertencias como «Pídeme lo que quieras. / Pero eso no (en la espalda)» o «No estoy sola». Últimamente, según una noticia aparecida en Terra.com el 28 de febrero de 2007, se ha comercializado una camiseta innovadora en el ámbito del ligue:

Una camiseta con un nombre en clave y un número de identificación bastan para vencer la timidez y enviar un mensaje anónimo al teléfono de la persona que a uno le gusta, según el estilo "Shyno" ${ }^{2}$ la nueva forma de flirtear, de coquetear en Italia.

La camiseta, creada por el estudiante de medicina Simone Gianicola, tiene un mensaje directo, «no-shyne» (sin timidez en inglés), y puede comprarse a través de Internet o en numerosas tiendas italianas al precio de 38 euros (unos 50 dólares).

Trae, además, una tarjeta similar a la de las recargas telefónicas, que contiene un código secreto con el que se conecta el número de la camiseta al teléfono celular del propietario.

Con este método, se pueden enviar por teléfono móvil mensajes de texto o vídeo-mensajes de manera totalmente anónima y el que los recibe puede responder o no y comenzar el juego de la «caza», como lo denominan. [...]

El joven Gianicola, que ha convertido la ropa en un medio de comunicación, tuvo la idea en 2003 cuando estaba en una fiesta y no supo cómo ponerse en contacto con una chica que le gustaba.

También juegan un papel significativo en la comunicación textil las camisetas filosóficas del tipo:

\section{Busca en tu intimidad \\ Cualquier creencia. \\ Vive y deja vivir \\ Sin contaminar.}

${ }^{2}$ El primer experimento tuvo lugar en Formentera, donde se repartieron mil camisetas y en una semana se generaron más de 14.000 mensajes entre los que las llevaban. 
En estas prendas se transmiten sobre todo formas de entender la vida. Dentro de este grupo sobresalen, entre otras, las camisetas con frases a favor del carpe diem: «Fuma y bebe, que la vida es breve», cuya idea de partida se resume en «La vida son tres días: dos de fiesta y uno de resaka». Estas prendas las portan personas contrarias a seguir un estilo de vida saludable, detractoras del «morir sanos», que llegan a exhibir en sus torsos mensajes como «El día que leí que el tabaco era malo para la salud dejé de leer». Frente a éstas se encuentran las personas que se cuidan, que no quieren destrozar su cuerpo, sino mantenerlo lo mejor posible durante el mayor número de años. Para conseguir su objetivo defienden entre otras cosas la austeridad y el seguimiento de una dieta sana, de ahí que en sus camisetas se lean consejos como «Pon brócoli en tu vida». Sin embargo, no es fácil seguir una correcta alimentación, puesto que como se lee en alguna de estas prendas «Todo lo que me gusta o es ilegal, o es inmoral, o engorda». Ante la desesperación por no poder comer lo que le apetece hay gente que se rebela y se burla de todas estas dietas restrictivas proponiendo otros regímenes descabellados del estilo de «My idea of a balanced diet is a beer in each hand».

Para completar esta lista de funciones nos falta referirnos a las camisetas estéticas, las que se caracterizan por su belleza expresiva. Pertenecen a esta clase las que llevan impresos textos como el siguiente:

\section{El amor es un magual \\ Con diferentes empeños \\ Más grandes o más pequeños \\ Pero jamasmente igual \\ Raquel Olivera.}

Esta clase de prendas pueden ser de creación propia o pueden comprarse. Así, como señala P. Calefato (2002: 81), entre las empresas italianas dedicadas a la comercialización de estas últimas destaca Parole di cotone (Palabras de algodón), que adorna sus camisetas con «refinados textos literarios y frases célebres de películas de «culto» para vestir». Entre las españolas sobresale Pompas de Papel (www.pompasdepapel.com), conocida por la venta de las camisetas literarias, que consisten en un estampado formado por «un motivo literario más un diseño acorde con una misma idea». Su objetivo, por tanto, es unir la belleza narrativa con la fantasía del diseño. Y así, entre su repertorio, figura la imagen de unos troncos de árboles de los que caen corcheas que se combinan con la frase de R. Tagore: «El bosque sería muy triste si sólo cantaran los pájaros que mejor lo hacen»; o la que lleva plasmado un corazón negro que incluye el siguiente fragmento de O. Wilde: «A veces 
podemos pasarnos años sin vivir en absoluto, y de pronto toda nuestra vida se concentra en un solo instante».

\subsection{Forma}

Al analizar las camisetas desde la perspectiva formal advertimos que no sólo hay que prestar atención a las frases, sino también a otros aspectos extralingüísticos como el color, las imágenes expuestas en estas telas y la ubicación de las palabras impresas. Estos tres elementos suelen complementar el contenido de los mensajes estampados en estas prendas. En el ámbito cromático se observa que el lenguaje de los colores resulta básico a la hora de interpretar muchas de las camisetas escritas: ni la respuesta del receptor ni las connotaciones de un color son idénticas a las de otro. Por ejemplo, en referencia al rojo, A. López Eire y J. de Santiago Guervós (2000: 101) señalan que:

El rojo es un color que viene hacia nosotros, avanza. Color turgente que acapara la atención y desbanca a todos los colores circundantes. La naturaleza agresiva del rojo ha estado relacionada siempre con las ideas de combate. Puede asociarse con la carne y la emoción: desde el amor y el coraje hasta la lujuria, el crimen, la rabia y la alegría. Obviamente hay que añadirle a su significación general las connotaciones que comparte cada sociedad en cuanto a la presencia del rojo. No tendrá el mismo significado para un soviético que para un francés, pues las experiencias ligadas al color pueden variar según las culturas y las propias experiencias.

Tras la lectura de este fragmento, podemos llegar a entender por qué nos encontramos camisetas de color rojo con el rostro del Ché junto a un texto como:

El revolucionario verdadero está guiado por grandes sentimientos de amor. Hay que tener una gran dosis de humanidad, una gran dosis del sentido de la justicia y de la verdad.

Los colores también se asocian con determinados grupos y territorios. Por ejemplo, la camiseta para animar a la selección española en el Eurobasket de 2007, era de color rojo y la exclamación «iSomos la eñe!», que aparecía estampada, de color amarillo. Parece claro, que ambos colores, los de la bandera nacional, junto con la letra $\tilde{n}$, la típica de nuestra lengua, sustituyen a la palabra España. ¿Sería lo mismo si esta prenda en vez del amarillo y el rojo combinara el marrón y el verde? 
En cuanto a las imágenes que acompañan al texto advertimos que hay dibujos, logos, símbolos y fotos de todo tipo: desde la lengua de los Rollings hasta la cara de Einstein, pasando por el famoso toro español. Estos iconos aparecen, bien solos, o bien acompañados de un mensaje. Con o sin palabras, la persona que lleva el rostro de una persona famosa, como Marilyn Monroe, está manifestando implícitamente su estima hacia ella. En palabras de Ángel López:

[...] la persona que lleva grabado el rostro de Marilyn Monroe no sólo está expresando su admiración por la artista de cine, está proclamando que comparte los valores simbólicos que ella representaba (1998: 116).

El problema que plantean algunos de los motivos que se exhiben en estas telas es que pueden generar polémica. Por ejemplo, las autoridades francesas han prohibido llevar en los centros docentes camisetas que porten el icono del cannabis. En la página 10 del diario gratuito 20 minutos del 11-9-2006 se aludía a este hecho:

Francia prohíbe la hoja de "maría" en las camisetas.

Los estudiantes no podrán usar ninguna prenda o complemento de bisutería que «presente el consumo de drogas bajo una luz favorable» [...]

La campaña, impulsada por los ministerios de Educación, Justicia e Interior, pretende imponer a partir de este curso escolar, que en Francia empezó hace una semana, un modelo de «tolerancia cero» hacia cualquier apología del porro y otros derivados del cannabis.

El Ministerio de Educación asegura que su pretensión última es eliminar la «laxitud» en los centros escolares mediante la prohibición de cualquier prenda u objeto que «presente el consumo de drogas bajo una luz favorable». «Comportamiento delictivo».

Si un alumno francés lleva al instituto una camiseta estampada con la popularísima hoja de cinco puntas de la planta de «maría», el director debe invitarlo a que se la quite o se la ponga, dada la vuelta hacia dentro. A continuación debe informar a los padres para «ponerles frente a sus responsabilidades». Si el «comportamiento delictivo» persiste, llamará a los gendarmes.

Otro aspecto extralingüístico fundamental es la ubicación de las frases. La situación que ocupan las palabras en una camiseta es muy importante. Así lo reconoce A. López García, al afirmar:

Existen camisetas con la impresión del motivo delante, en el pecho, y camisetas con la impresión detrás, en la espalda, aunque en algunos casos se den las dos localizaciones al mismo tiempo. No es indiferente que el portador de 
la camiseta pueda ver el motivo representado en la misma de refilón, lo muestre implícitamente a otras personas cada vez que se dirige a ellas y advierta cómo le dirigen miradas furtivas, o que, por el contrario, llegue a olvidarse del mismo. En el primer caso tenemos una simbología consciente, en el segundo algo muy parecido al relegamiento de ciertos valores al inconsciente. Se trata claro está de un inconsciente muy particular, pues la camiseta no ha dejado de ser elegida por su portador y ésta puede ver el motivo oculto cada vez que se la pone (1998: 117-118).

Además de las camisetas que llevan las frases en el pecho y de las que las lucen en la espalda, existe una tercera modalidad, las que exhiben una parte del mensaje delante y otra detrás, que suelen ser de carácter burlesco. Un caso ilustrativo es la camiseta que lucen algunas jóvenes en cuyo torso se lee «Pídeme lo que quieras» y en cuya espalda se advierte «Pero eso no».

Desde el punto de vista verbal y concretamente en el ámbito ortográfico lo más destacado es el predominio de las letras mayúsculas para facilitar la lectura del mensaje: «ESTOY PARA COMERME». Este tipo de letra se emplea, por otra parte, para enfatizar, para gritar de manera silenciosa. También merece un comentario el uso de la trasgresión ortográfica intencionada: «Onze años en la unibersidad i a ora...». La persona que ha escrito esta frase no ignora la norma, sino que juega con ella para llamar la atención, en este caso para provocar la sonrisa del receptor. Otro recurso chocante y habitual en los escritos de estas prendas es el empleo de las nuevas grafías que se han introducido gracias a la expansión del ciberlenguaje: «J@zz».

Desde la perspectiva fonética sobresalen las frases interjectivas, las acabadas con el signo exclamativo: «Just Divorced. Warning! Free Woman». La fuerza del mensaje expresado es directamente proporcional al número de exclamaciones empleadas. Es decir, la multiplicación de signos de admiración es como una especie de subrayado expresivo que ayuda a enfatizar determinadas partes del texto estampado: «Botellón no!!! Hay poco y somos muchos».

En el terreno morfosintáctico subrayaríamos que, al igual que los anuncios, las camisetas con palabras se distinguen por la brevedad y la concisión. No olvidemos que los textos se han de adaptar a las limitaciones impuestas por la dimensión de la camiseta y por la capacidad de captación de los receptores. Estas pizarras de tela se distinguen, por tanto, porque en ellas se realiza un esfuerzo de síntesis verbal con el propósito de que el mensaje deseado quepa y de que éste se pueda leer de un vistazo. No es de extrañar, pues, que abunden los mecanismos encaminados a la economía lingüística 
como el uso de la elipsis («Mi ex es gilipollas»), el lenguaje de los móviles («Estoy sola, a k esperas») o el empleo de dibujos («I $\vee$ NY») o números («AH2ORRA») para utilizar las menos letras posibles.

Siguiendo los criterios en los que se basa A. Ferraz Martínez (2000: 36) para el estudio de la publicidad, podemos distinguir tres tipos de mensaje en las camisetas: aquellas en las que éste queda reducido a la marca («Nike»), las que lucen una breve frase o construcción condensada ( «Haz el amor y no la guerra») y las que muestran un texto desarrollado como el siguiente presagio de los indios Cree de Canadá:

Sólo después de que haya sido cortado el último árbol, sólo después de que haya sido envenenado el último río, sólo después de que haya sido pescado el último pez, sólo entonces descubrirás que el dinero no se puede comer.

La lectura de esta última clase de camisetas resulta dificultosa debido a la extensión del texto que exhibe. Sólo una persona, que se mantenga a corta distancia y parada, puede captar el mensaje expuesto anteriormente.

En el plano léxico-semántico, resaltaríamos los mecanismos empleados sobre todo en las camisetas que tratan de ser como un puñetazo en el ojo del que las contempla. Entre éstos sobresale la reinterpretación de siglas ( «FBI. Female Body Inspector»), las etimologías populares («Soy bisexual. Las tías a pares»), los eufemismos («iYo no estoy gordo, sólo estoy muy fuerte!»), los disfemismos («No soy un alcohólico sino un borracho!»), y las palabras ambiguas («Soy un sol. Salgo...y me pongo»), que se usan con la intención de atraer miradas. Con respecto a este último recurso lingüístico, y para evitar situaciones embarazosas, se aconseja leer bien las imprimaciones que decoran las camisetas ya que, en caso contrario, se puede llegar a malentendidos semejantes al descrito por E. del Valle:

-Bueno, Santi —le dije cuando ya se marchaban-. A ver si me haces una camiseta como ésa que llevas.

-Tú lo flipas mamá. ¿Adónde vas con eso? —me miró asombrado Bruno.

- Mira tú, a cualquier sitio... —respondí indignada— ¿O es que no puedo ir por la vida diciendo «Abajo las drogas»?

-Pero ¿tú la has visto bien? - respondió mientras le daba la vuelta a Santi para que le viera la espalda. Y es que la leyenda de su camiseta seguía por detrás: Firmado los del sótano.

Y se marcharon muertos de risa (2004: 29-30). 


\subsection{Uso}

En este apartado nos centraremos en cómo se elige una camiseta para lucirla en una situación comunicativa determinada. El primer rasgo que llama la atención es la enorme variedad de estas prendas. Si tenemos en cuenta la forma, las hay con manga corta y con manga larga, sin mangas, con tirantes ${ }^{3}$, etc. Si nos basamos en el mensaje, podemos distinguir entre las personalizadas y las no personalizadas. El método para obtener una camiseta particular consiste en el diseño propio, en decorarla uno mismo. De esta manera se llega a la exclusividad, a la obtención de una prenda especial que ayuda a diferenciarse del resto. Para ello se ha de comprar una camiseta y darle un aire nuevo. Éste es el procedimiento seguido por el hijo de la protagonista del libro Todas las tribulaciones de una madre sufridora, de A. Vallejo-Nájera:

[...] mi niño todavía rebosa candidez. Allí le veo, parado en medio de la cocina, con su nueva adquisición que le llega por las rodillas. De nada sirve que se trate de una camiseta sin mangas. El tirante le cubre la totalidad del hombro y la sisa casi le alcanza la cintura.

— ¿Y eso? — señalo la decoración.

-Me lo he pintado yo. ¿A que mola?

Para gloria de la humanidad, el arte de Javi ha sido plasmado en ambas caras de la camiseta. El derroche de ingenio me estremece. Por delante aparece, diseñada con spray de plata la siguiente frase revelación:

Amo los ordenatas comprensivos y...

Obsérvese el suspense que mi niño logra con los puntos al final. Menos mal que el enigma queda resuelto, esta vez con spray rojo, en la parte trasera:

...el sexo interactivo (2006: 243-244).

Otra manera de conseguir una camiseta a la carta es acudir a determinadas tiendas. En ellas el cliente, para lograr lo que busca, ha de seguir las pautas que aparecen escritas en un cartel de la entrada:

Coge una camiseta

Busca una idea

$Y$ en un plis plas, en tan solo 6 segundos,

Tu prenda favorita.

${ }^{3}$ Este tipo de camiseta las usan los culturistas, por ejemplo, para enseñar y destacar las partes de su cuerpo que consideran más sobresalientes: sus músculos. 
Desde el verano de 2004 existe otra posibilidad para lucir una de estas prendas personalizadas, aunque resulta un poco más cara que la anterior. A ella se refería el artículo «Llega la ropa comunicante», publicado en el Suplemento Ariadn@ de El Mundo, el 18 de julio de 2004. Se trata de una pantalla flexible incorporada a la ropa que muestra imágenes, vídeos o textos. Gracias a ella y mediante la intervención de un móvil, se van exhibiendo los mensajes que uno desea en función de su estado de humor, de la compañía o de la situación comunicativa en la que participa. La razón de ser de este tipo de camisetas la expone claramente Emeric Mourot, director del proyecto, al señalar:

Si la ropa de los adolescentes de medio mundo lleva publicidad de Nike, Adidas o Coca-Cola, ¿por qué no facilitarles la vida para que reivindiquen lo que quieran sin tener decenas de camisetas con distintos mensajes?

Expuestas las posibilidades de estampación con las que contamos, pasamos a comentar cómo se debe escoger el mensaje que se quiere lucir en una camiseta para que sea eficaz. A la hora de elegir el texto que ha de adornar esta prenda conviene no olvidar que su contenido está determinado por las variables sociales del portador (edad, sexo, profesión, clase social, etc.) y por la situación comunicativa en la que se va a exhibir.

Por lo que respecta a las características sociales, parece evidente que al escoger los mensajes, además de tener en cuenta lo que deseamos expresar, tenemos presente lo que se espera de nosotros. Así, no creemos que un señor de setenta años se enfunde una camiseta con la frase «I'm a Sex Machine», ni que una joven de quince se ponga otra que diga «Amo a mi hipoteca». El sexo constituye otro rasgo determinante en el adorno con palabras de estas prendas. No hemos visto a ninguna joven ni señora en cuyo vientre se lea «Barriga patrocinada por Heineken» o «Esto no es una barriga. Es una camiseta con relieve». Sí que hemos leído, en cambio, estas frases en torsos masculinos porque el exceso de peso no se suele ver de la misma forma en un hombre y en una mujer ${ }^{4}$.

Otro rasgo que influye en el contenido de la camiseta es la profesión. ¿A qué gremio puede pertenecer la persona que exhibe en su pecho la leyenda «Voy forrao de chuletas!»?. Evidentemente a la comunidad estudiantil. En palabras de la empresa que la vende en Internet:

${ }^{4}$ No es habitual encontrar mujeres que presuman de sobrepeso, que al decirles iQué gorda estás! o ¡Menuda Barriga! contesten sin ofenderse y acariciándose la tripa: ;Mi trabajo me ha costado de criar! o ¡Es la curva de la felicidad!, o incluso en tono jocoso: ¿Qué, esto?, ;pero si es un cementerio de mariscos! Estos comentarios sí que se oyen en bocas masculinas. 
Esta camiseta va dirigida a vosotros, universitarios. Sabemos lo duro que es para vosotros la época de exámenes, y lo pesados que son los profesores, por esto hemos diseñado esta camiseta para reivindicar el uso de las chuletas. ¿Quién no ha copiado alguna vez en un examen? Qué digo.... ¿quién no ha copiado miles de veces?! Si eres estudiante, ésta es tu camiseta. ¡Especial selectividad! (http://www.dirtyfashion.com/producto.php?item=0088).

También la clase social tiene su influencia en las inscripciones de las prendas que estamos estudiando. No es lo mismo vestirse con una camiseta que dice: «Me costó 5 euros pero no me la quito de encima» que con otra que lleva estampadas las iniciales $« \mathrm{D} \& \mathrm{G} »$.

Aparte de estas variables y de otras en las que no vamos a entrar por falta de espacio, también el contexto, o sea el interlocutor, el canal, el ambiente o la finalidad, se consideran determinantes a la hora de lucir con éxito una camiseta escrita. Por ejemplo, la lengua a utilizar se elegirá en función del público al que vaya dirigido. No tiene sentido llevar una camiseta en la que aparece «Mare per tu no pare. Don't Stop», si los destinatarios no saben catalán. Tampoco conseguirá lo que quiere la joven que luce en su torso la leyenda «I'M Sexy But I'm not Easy» si se la lleva ante interlocutores que desconocen el inglés. En cuanto al canal hemos de advertir que, además de las camisetas que se llevan para exhibirse cara a cara, están las que se lucen para ser televisadas. Un ejemplo ilustrativo de estas últimas son las que llevan debajo del uniforme oficial algunos jugadores de fútbol cuando disputan un partido oficial en presencia de las cámaras de televisión. Estas prendas se las ponen normalmente los delanteros con el propósito de rendir homenaje a determinadas personas. Su funcionamiento es el siguiente: al marcar un gol el deportista se destapa el torso y exhibe la tela oculta con el mensaje, consciente de que se leerá gracias a una cámara que se fijará en él y lo reproducirá. Por ejemplo, a los pocos días del fallecimiento del futbolista Antonio Puerta, uno de sus antiguos compañeros al materializar un tanto exhibió una camiseta interior en la que se leía «Puerta, hermano, DEP. Va por ti». Si esta prenda se hubiese enseñado en un campo sin cámaras, el mensaje hubiese pasado inadvertido porque seguramente nadie lo hubiese podido leer. El ambiente es otro factor a tener en cuenta cuando uno porta una camiseta escrita con la intención de que se lea. Cuando éste no se toma en consideración se puede llegar a situaciones incluso tensas. Por ejemplo, causó un gran revuelo mediático la camiseta de una profesora de filosofía de un instituto público de San Sebastián de los Reyes. La docente se presentó en clase con la siguiente leyenda en su torso: «Fórmula matemática: $\mathrm{HB}+\mathrm{ZP}=\mathrm{HP}$ », y los estudiantes y sus padres la denunciaron porque «portaba una camiseta en la 
que emitió a través de su vestimenta una opinión política donde no procedía». El último aspecto digno de mención al hablar de la situación comunicativa es la finalidad. No es lo mismo ponerse una camiseta para pasar un buen rato, como ocurre en las despedidas de solter@, en la que la novia puede lucir frases del tipo «Aprovechad chicos, es mi última noche», que llevar una de estas prendas para concienciar, como sucede con los llamados mediadores del ocio, que durante las noches de marcha valenciana, al recorrer las zonas acústicamente saturadas, llevan unas camisetas que dicen: «Diviértete sin molestar» ${ }^{5}$.

Una persona al vestir una camiseta adornada con palabras puede recibir al menos tres respuestas. La primera, es positiva, y consiste en la lectura del mensaje expuesto e incluso, a veces, una sonrisa por parte de la gente. La segunda respuesta posible es la indiferencia: la leyenda que la persona expone en su torso pasa totalmente desapercibida, no consigue atrapar la mirada de los ciudadanos. La tercera posibilidad es que la prenda que se lleva desencadene una respuesta inesperada como la que sufrió la hija de Elvis Presley, Lisa Marie Presley, que desató las iras de las organizaciones contra los malos tratos, al aparecer en la entrega de unos premios con una camiseta en la que se leía: «Bite me!».

\section{CONCLUSIONES}

Tras esta reflexión sobre el lenguaje de las camisetas hemos llegado a las siguientes conclusiones:

a) Estas prendas se han convertido en un poderoso soporte para la comunicación actual, ya que constituyen un canal sencillo, cómodo y barato. Estas telas, que dan colorido a nuestros torsos y espaldas, no sólo son empleadas por las empresas e instituciones para promocionarse, sino que últimamente son utilizadas también por los particulares para darse a conocer.

b) Estas piezas de ropa, que nos visten y nos desnudan («dime qué camiseta llevas y te diré quién eres»), aparte de hablar de nosotros, dicen muchas cosas de la sociedad en que vivimos. Si nos fijamos en

${ }^{5}$ La camiseta con esta frase constituye el uniforme que llevan estas personas con el propósito de conciliar el derecho a divertirse de los jóvenes con el derecho a descansar de los vecinos. Se trata del mensaje de una campaña contra el ruido en la que los participantes pretenden informar a la juventud de que es posible pasárselo bien sin incordiar al vecindario. 
ellas advertimos fácilmente que nos encontramos en un entorno caracterizado por el consumismo, la globalización, las nuevas tecnologías, el poder de los medios de comunicación, el ritmo desenfrenado, el culto al cuerpo...

c) Desde la perspectiva funcional, las camisetas se distinguen por su polivalencia: lo mismo sirven para vender una marca, o para seducir, que para protestar, recaudar fondos para una causa justa, para exponer el ideal de vida del portador, para conmemorar determinados acontecimientos o, simplemente, para alegrar la vista.

d) Desde el punto de vista formal, las leyendas de las camisetas se caracterizan, a grandes rasgos, por su brevedad (han de ser captadas de un vistazo) y por su fuerza expresiva (han de llamar la atención para no pasar desapercibidas), de ahí que algunos las hayan definido como gritos sobre el cuerpo.

e) Para lucir estas prendas con éxito no sólo «hay que vestir como se piensa», sino que también «hay que pensar cómo se viste». Sabedores de que la elección de la ropa no depende sólo del gusto propio, sino también de lo que se espera de cada persona, antes de exhibir una camiseta escrita conviene que el portador o portadora, además de tener en cuenta sus características sociales, tenga presente la situación comunicativa en la que va a participar.

\section{REFERENCIAS BIBLIOGRÁFICAS}

AILES, R. (1993). Tú eres el mensaje. La comunicación con los demás a través de los gestos, la imagen y las palabras. Barcelona: Ediciones Paidós Ibérica.

CALEFATO, P. (2002). El sentido del vestir. Valencia: Engloba.

DEL VALLE, E. (2004). Un adolescente bajo mi techo. Barcelona: Grijalbo. ETXEBARRÍA, L. (2007). «Camisetas y palabras». En ADN, 18-06, 24.

FERRAZ MARTÍNEZ, A. (2000). El lenguaje de la publicidad. Madrid: Arco/Libros.

GARCÍA FERNÁNDEZ, J. L. (2000). Comunicación no verbal. Periodismo y medios audiovisuales. Madrid: Editorial Universitas.

GAVARRÓN, L. (2003). La mística de la moda. Valencia: Engloba. 
HOGUE, L. L. (2000). La comunicación. Un arte que se aprende. Santander: Editorial Sal Terrae.

KLEIN, N. (2001). No logo. Barcelona: Paidós.

LÓPEZ EIRE, A. y DE SANTIAGO GUERVÓS, J. (2000). Retórica y comunicación política. Madrid: Cátedra.

LÓPEZ GARCÍA, Á. (1998). «Mis hijos llevan ropa de marca». En su obra En medio de los medios, 103-119. Zaragoza: Prames.

LURIE, A. (1994). El lenguaje de la moda. Barcelona: Ediciones Paidós Ibérica.

MORANT, R. (2003). «Comunicación institucional y mensajes de asfalto». Lynx 2, 141-159.

- (2005). «La comunicación nuestra de cada día: lenguajes para todo». En Palabras, norma, discurso: en memoria de Fernando Lázaro Carreter, Luis Santos (coord.), 843-852. Salamanca: Universidad de Salamanca.

- (2007). «La calle: un maremágnum comunicativo». En La incidencia del contexto en los discursos, Enric Serra (ed.). Lynx, Annexa 14, 151-175.

RIVIÈRE, M. (2002). «Moda de los jóvenes: un lenguaje adulterado». En Comunicación y cultura juvenil, Félix Rodríguez (ed.), 87-92. Barcelona: Ariel.

SQUICCIARINO, N. (1990). El vestido habla: consideraciones psicosociológicas sobre la indumentaria. Madrid: Cátedra.

TANNEN, D. (1999). ;Yo no quise decir eso! Barcelona: Paidós Ibérica.

UMBRAL, F. (1997). «Camisetas solidarias». En El Mundo, 18-04, www.elmundo.es/papel/hemeroteca/1997/04/18/ultima/251804.html

VALLEJO-NÁJERA, A. (2006). Todas las tribulaciones de una madre sufridora. Madrid: Temas de Hoy. 